\title{
Effects of Surface Characteristics of Polymeric Nanocapsules on the Pharmacokinetics and Efficacy of Antimalarial Quinine
}

This article was published in the following Dove Press journal: International Journal of Nanomedicine

\author{
Luana Roberta Michels (iD) \\ Tamara Ramos Maciel (D) ${ }^{\prime}$ \\ Kelly Ayumi Nakama (D) \\ Flavia Elizabete Guerra \\ Teixeira $(\mathbb{D})^{\prime}$ \\ Felipe Barbosa de Carvalho (D) ${ }^{1}$ \\ André Gundel (D) ${ }^{2}$ \\ Bibiana Verlindo de Araujo $\mathbb{1}^{3}$ \\ Sandra Elisa Haas (D) 1 \\ 'Pharmaceutical Sciences Post Graduate \\ Program, Pharmacy Course, Federal \\ University of Pampa, UNIPAMPA, \\ Uruguaiana, RS, Brazil; ${ }^{2}$ Campus Bagé, \\ Federal University of Pampa, UNIPAMPA, \\ Bagé, RS 1650, Brazil; ${ }^{3}$ Pharmaceutical \\ Sciences Post Graduate Program, College \\ of Pharmacy, Federal University of Rio \\ Grande do Sul, Porto Alegre, RS 2752, \\ Brazil
}

Correspondence: Sandra Elisa Haas Curso de Farmácia, Universidade Federal do Pampa, UNIPAMPA, Uruguaiana, Brazil Tel +555539110200

Email sandrahaas@unipampa.edu.br

\begin{abstract}
Introduction: The surface charge of nanoparticles, such as nanospheres (NS) and nanocapsules (NC), has been studied with the purpose of improving the in vivo performance of drugs. The aim of this study was to develop, characterize, and evaluate the in vitro antimalarial efficacy of NCP80 and NSP80 (polysorbate coated) or NCEUD and NSEUD (prepared with Eudragit RS 100) loading quinine (QN).
\end{abstract}

Methods: Formulations were prepared by the nanoprecipitation method, followed by wide physicochemical characterization. Antimalarial activity in Plasmodium berghei-infected mice and populational pharmacokinetics (PopPK) in rats were evaluated.

Results: The formulations showed a nanometric range (between $138 \pm 3.8$ to $201 \pm 23.0$ $\mathrm{nm})$, zeta potential $(\mathrm{mV})$ of $-33.1 \pm 0.7$ (NCP80), $-30.5 \pm 1$ (UNCP80), $-25.5 \pm 1$ (NSP80), $-20 \pm 0.3$ (UNSP80), $4.61 \pm 1$ (NCEUD), $14.1 \pm 0.9$ (UNCEUD), $2.86 \pm 0.3$ (NSEUD) and $2.84 \pm 0.6$ (UNSEUD), content close to $100 \%$, and good QN protection against UVA light. There was a twofold increase in the penetration of QN into infected erythrocytes with NC compared to that with NS. There was a significant increase in $t_{1 / 2}$ for all NC evaluated compared to that of Free-QN, due to changes in Vdss. PopPK analysis showed that NCP80 acted as a covariate to Q (intercompartmental clearance) and V2 (volume of distribution in the peripheral compartment). For NCEUD, V1 and Q were modified after QN nanoencapsulation. Regarding in vivo efficacy, NCEUD increased the survival of mice unlike Free-QN. Conclusion: Cationic nanocapsules modified the pharmacology of QN, presenting a potential alternative for malaria treatment.

Keywords: quinine, malaria, nanocapsules, nanospheres, antimalarial efficacy

\section{Introduction}

Malaria remains the most prevalent parasitic disease in the world. It is caused by protozoa of the genus Plasmodium and is transmitted by female Anopheles mosquitoes. ${ }^{1-3}$ The increasing incidence of malaria worldwide and the increasing resistance to existing antimalarial drugs make the development of new strategies to combat the parasite an urgent research topic. In 2017, there were an estimated 216 million cases of malaria in 87 countries, an increase of 5 million cases over 2015, with deaths from malaria reaching 435.000 in 2017, a similar number (446.000) to 2015. ${ }^{1}$ Furthermore, total funding for the control and elimination of malaria reached an estimated US\$ 3.1 billion in 2017. Contributions from the governments of endemic countries amounted to US\$ 900 million, representing $28 \%$ of all funding. ${ }^{1}$ 
Malaria treatment should be curative in order to prevent disease progression, relapse (due to the survival of erythrocytic forms in hepatocytes), malarial transmission, and the development of drug resistance. ${ }^{2,3}$ Current treatments are hampered by the emergence of parasites with resistance to antimalarial drugs, such as chloroquine, ${ }^{4-6}$ leading to the utilization of concomitant drugs to increase antimalarial efficacy, such as quinine (QN) plus doxycycline or tetracycline; however, this requires a 7-day course and is poorly tolerated, due to serious side effects caused as cardiotoxicity and the development of cinchonism syndrome. ${ }^{6,7}$ Moreover, the high doses required for i.v. administration can induce severe and even fatal cardiac arrhythmias and hypotension. ${ }^{8,9}$ Consequently, several strategies have been proposed to enhance the bioavailability and efficacy of drugs. The use of colloidal carriers such as nanocapsules as delivery vehicles has been effective at improving the efficacy of drugs, including antimalarials; ${ }^{10-12}$ one strategy for targeting drugs to infected erythrocytes is the use of intravenously administered nanocarriers. . $^{13,14}$

Our research group has developed nanocapsules as antimalarial drug delivery systems. Recently, we demonstrated that co-encapsulation of QN and curcumin significantly reduced $P$. falciparum parasitemia, ${ }^{15}$ and that nanoencapsulation improved the efficacy of QN when coencapsulated with Curcuma oil. ${ }^{16}$ In addition, we observed a potential reduction in the toxicity of QN-loaded nanocapsules (Q-NC) in ovarian tissue and a partial reduction in the testes of male and female rats, ${ }^{17}$ representing an alternative to alleviate the side effects associated with QN in the reproductive system. We are interested in exploring the ability of these systems, with a new coating, to potentiate the activity of QN alone, without co-encapsulation with another antimalarial agent.

Surface modifications of nanoparticles using various agents can help to improve properties for different applications in the field of nanotechnology. ${ }^{18-20}$ This has been widely explored, and shown to modify the in vitro and in vivo performance of drugs, ${ }^{21,22}$ including the efficiency of intravenously administered QN. Thus, it may be possible to generate changes in hydrophilicity/hydrophobicity and the surface charge of systems, inducing different interactions with the living system and consequently a biological response associated with drugs. ${ }^{18}$ It is also possible to reduce the surface tension between particles and cells, allowing greater contact, through the use of cationic polymers such as Eudragit ${ }^{\circledR}$ RS100 (EUD), a poly(ethyl methacrylate-comethyl methacrylate-co-trimethyl ammonioethyl methacrylate chloride) in proportion 1:2:0.1, to increase the interaction of drug with cell membranes, ${ }^{23}$ and by coating nanoparticles with surfactants such as polysorbate 80 (Tween $80^{\circledR}, \mathrm{P} 80$ ), which have an amphiphilic character. ${ }^{24}$ These surfacemodified characteristics of nanoparticles would be expected to act like circulate particles of $\mathrm{QN}$, releasing the drug progressively and therefore increasing its availability to parasitized red blood cells (RBC), or by increasing the interaction with the cell membrane by different charge interactions.

Thus, the aim of the present study was to assess the activity of QN on the surface-modified characteristics of nanoparticles in vitro and in vivo in Plasmodium bergheiinfected mice. The use of different systems, such as quinineloaded nanocapsules (NC) and nanospheres (NS) coated by P80 or by EUD, is expected to improve the efficiency of intravenously administered QN. To relate the levels of circulating drug to the efficacy of nanoparticles with different surface-modifications, the pharmacokinetic profile of QN was evaluated using $P$. berghei-infected Wistar rats.

\section{Materials and Methods}

\section{Chemicals and Reagents}

Quinine (QN) (90\% purity), cimetidine, polysorbate 80 , Span $60^{\circledR}$, and poly ( $\varepsilon$-caprolactone) (PCL) were obtained from Sigma Aldrich Ltd (São Paulo, Brazil). Lipoid S45 ${ }^{\circledR}$ was purchased from Lipid Ingredients in Brazil. Acetonitrile and methanol were obtained from Tedia ${ }^{\circledR}$ (Fairfield, USA). Purified water was prepared using a Milli-Q Plus (Millipore, Bedford, USA). All other reagents and chemicals used were of pharmaceutical or special analytical grade.

\section{Preparation and Characterization of Quinine-Loaded Nanoparticles}

The nanoparticles were prepared by the interfacial deposition of polymer. ${ }^{25}$ The organic phase was composed of PCL (NSP80 and NCP80) or EUD (NSEUD and NCEUD), capric/caprylic triglycerides (NCP80 and NCEUD), Lipoid S45 ${ }^{\circledR}$ (NSP80 and NCP80), Span $60^{\circledR}$ (NSEUD and NCEUD), and quinine (QN) $(2 \mathrm{mg} / \mathrm{mL})$ dissolved in acetone $\left(45 \pm 1^{\circ} \mathrm{C}\right)$. After dissolution, this phase was added to the aqueous phase composed of distilled water and polysorbate 80. After nanoprecipitation, the acetone and part of the water were removed by evaporation under reduced pressure up to the desired volume. Unloaded nanocapsules (UNC) and nanospheres (UNS) were prepared in the same manner, omitting the drug. All formulations were prepared in triplicate. The size and polydispersity of nanoparticles were measured by laser diffraction using a Mastersizer $2000\left(\right.$ Malvern $\left.^{\circledR}\right)$. 
The $\zeta$-potentials were determined by electrophoretic mobility at $25^{\circ} \mathrm{C}$ after appropriate dilution in water using a Zetasizer $\left(\right.$ Malvern $^{\circledR}$ ) equipment. The $\mathrm{pH}$ values were determined using a potentiometer $\left(\mathrm{HANNA}^{\circledR}\right){ }^{22}$

The concentration of QN nanoparticles was assayed by HPLC using a previously validated method. ${ }^{26}$ The analysis was performed on a Shimadzu LC system (Kyoto, Japan), which consisted of a LC-20AT pump, an SPD-M20A photodiode array (PDA) detector, a CBM-20A system controller, a DGU-20A3 degasser, and a SIL-20A autosampler. Chromatographic separation was achieved on a $5 \mu \mathrm{m}$ Waters RP-18 column $(4.6 \times 300 \mathrm{~mm})$, with a guard column $(4 \times 3 \mathrm{~mm}$ i.d.) packed with the same material. The mobile phase was composed of acetonitrile:water:triethylamine (60:40:0.01, v/v/ v). The aqueous phase was adjusted to $\mathrm{pH} 3.0$ with phosphoric acid. The flow rate was $1.0 \mathrm{~mL} / \mathrm{min}$ and quinine was detected at $232 \mathrm{~nm}$ after injection of $20 \mu \mathrm{L}$. The encapsulation efficiency of QN was determined by ultrafiltration-centrifugation (Ultrafree $^{\circledR}$, MC Millipore 10.000) and total QN was determined after dissolution of nanoparticles with acetonitrile. The entrapped QNs were calculated from the difference between the total and free drug concentrations. ${ }^{14}$

\section{Photodegradation Kinetics and Determination of Reaction Order}

Photochemical stability was measured by exposing the free QN (F-QN) and samples NCP80, NSP80, NCEUD, and NSEUD to UV-A radiation (352 $\mathrm{nm})$. Samples $(\mathrm{n}=3)$ in transparent quartz cuvettes $(2 \mathrm{~mL})$ were placed in a mirrored safety cabinet for $8 \mathrm{~h}$ has previously described. ${ }^{26}$ Samples were collected at various time points $(0,1,2,3,4,5,6,7$, and $8 \mathrm{~h})$, diluted in acetonitrile to yield a final concentration of $20 \mu \mathrm{g} / \mathrm{mL}$, and filtered through a 0.45 $\mu \mathrm{m}$ membrane filter, before injection into HPLC-PDA.

The reaction order ( $\mathrm{k}$ ) was determined based on the residual concentration of QN with time (zero order); Log of residual QN concentration versus time (first order); and inverse of the QN residual concentration versus time (second-order). ${ }^{18}$ The suitability of the model for the experimental data was assessed with the Micro Math Scientist ${ }^{\mathrm{B}}$ program, comparing models based on parameters such as the model selection criterion (MSC), the correlation coefficient, and the consistency of the rate constant values. For the correlation coefficient (r) obtained, one that presents the nearest value of the unit is indicative of the reaction order $(\mathrm{R} \sim 1)$. With the $\mathrm{k}$ value, the half-life time $\left(\mathrm{t}^{1} / 2\right)$ was determined.

\section{Quinine Partition Coefficient in Erythrocytes}

This study was conducted to evaluate the binding of free and nanostructured QN to erythrocytes infected with $P$. berghei, as described previously. ${ }^{14}$ Blood from P. berghei-infected rats with a mean parasitemia of $9.25 \pm 1.5 \%$ was used. Blood was centrifuged at $6800 \mathrm{~g}(10 \mathrm{~min})$ and the plasma and buffy coat were discarded. Then, the erythrocytes were washed three times with $5 \%$ glucose solution $(\mathrm{pH}$ 7.4). Erythrocytes were resuspended in the same medium, and the hematocrit was adjusted to 0.48 . Free or nanostructured QN (NCP80, NSP80, NCEUD, and NSEUD) was added to the erythrocyte suspension to obtain a final concentration of $10 \mu \mathrm{g} / \mathrm{mL}$. After $30 \mathrm{~min}$ incubation $\left(37 \pm 1^{\circ} \mathrm{C}\right)$ the samples were centrifuged, and the supernatant was quantified by HPLC-PDA. The sediment was hemolyzed with distilled water $(1: 1, \mathrm{v} / \mathrm{v})$ and quantified. The partition coefficient of QN $(D)$ was determined by Equation (1): ${ }^{27}$

$$
D=\frac{A s-(C \sup \cdot V s \cdot(1-H))}{H \cdot V s \cdot C \sup }
$$

where As is the drug concentration added to the medium $(10 \mu \mathrm{g} / \mathrm{mL})$, Csup is the drug concentration in the supernatant, Vs is the final suspension volume, and $\mathrm{H}$ is the hematocrit.

\section{Atomic Force Microscopy (AFM)}

The morphology of the nanocapsules (NCP80, UNCP80, NCEUD, and UNCEUD) was examined by atomic force microscopy (AFM) (Agilent Technologies 5500 equipment). AFM images were acquired at room temperature, in non-contact mode using high-resolution probes, SSSNCL (Nanosensors, force constant $=48 \mathrm{~N} / \mathrm{m}$, resonance frequency $=154 \mathrm{kHz}$ ). Images were captured and analyzed with PicoView 1.14.4 software from Molecular Imaging Corporation and PicoImage 5.1. For the analysis, the solution was diluted in MilliQ water (1:50) and dropped onto freshly cleaved mica substrate.

\section{Pharmacokinetic Evaluation}

Prior to the start of the study, ethics approval was obtained from the UNIPAMPA Animal Care and Use Committee (010/ 2013) and animal experiments were performed in agreement with the guidelines given in "Principles of Laboratory Animal Care", National Institutes of Health (NIH) ${ }^{28}$ The pharmacokinetics of F-QN or nanoencapsulated QN from NCP80 and NCEUD was evaluated in Plasmodium berghei-infected male 
Wistar rats ( $\mathrm{n}=9$ per group). On day 0 , rats received $10^{8}$ $P$. berghei-infected erythrocytes (from mice) via i.v. administration. ${ }^{29}$ On day 7 post-infection, a single $20 \mathrm{mg} / \mathrm{kg}$ QN i.v. bolus dose was administered to rats via the lateral tail vein.

Blood samples were collected by lateral tail vein puncture and placed in heparinized tubes at predetermined times $(0.083,0.25,0.5,1,2,4,6,8,12,18,24$, and $30 \mathrm{~h})$ after i. $\mathrm{v}$. administration. Plasma was separated by centrifugation at $12,000 \mathrm{rpm}$ at $4 \pm 1^{\circ} \mathrm{C}$ for $10 \mathrm{~min}$ and quantified by HPLCMS. A rapid HPLC-MS analytical method was adapted for the determination of $\mathrm{QN}$ in rat plasma. Analyses were performed using a Waters ${ }^{\circledR} \mathrm{C} 18$ column $(50 \times 2.1 \mathrm{~mm} \times 5 \mu \mathrm{m})$ (Waters, Milford, EUA) with a guard column $(4 \times 3 \mathrm{~mm}$ i.d.) packed with the same material and eluted with acetonitrile: formic acid $0.1 \%(40: 60, \mathrm{v} / \mathrm{v})$.

The mobile phase was filtered through a $0.45 \mu \mathrm{m}$ membrane (Millipore, Bedford, USA), the flow rate was $0.45 \mathrm{~mL} / \mathrm{min}$, and the injection volume was $10 \mu \mathrm{L}$. Ionization technique atmospheric pressure (APCI) was in positive mode and the masses monitored were $325.0>$ 307.0 (quinine) and $252.8>159.0$ (cimetidine, internal standard, PI). Calibration curves in spiked plasma were linear over the concentration range $10-2.500 \mathrm{ng} / \mathrm{mL}$, with a determination coefficient of $>0.99$.

\section{Pharmacokinetic Analysis}

A non-compartmental (NCA) and compartmental approach was used to determine the pharmacokinetic parameters in plasma from rats of all experimental groups. Plasma concentrations versus time profiles were analyzed for each animal using Phoenix ${ }^{\circledR}$ software (Pharsight, Certara, USA). Differences in NCA-calculated pharmacokinetic parameters between the tested formulations were assessed by one-way ANOVA test $(\alpha=0.05)$ employing SigmaStat ${ }^{\circledR}$ version 3.5 (Systat Software, Point Richmond, USA).

\section{Population Pharmacokinetic (popPK) Modeling}

PopPK modeling was performed using Monolix software 4.3.3 (LIXOFT, Paris, France). A total of 216 plasma observations derived from 18 rats were included in the dataset for the popPK analysis.

The inter-individual variability on fixed-effect model parameters was described using an exponential model (Equation 2):

$$
P_{i}=P_{p o p} \cdot \exp \left(\eta_{i, P}\right)
$$

where $P_{i}$ represents the estimate for the individual lognormally distributed parameter; $\mathrm{P}_{\text {pop }}$ is the typical parameter estimate in the population, and $\eta_{\mathrm{i}, \mathrm{P}}$ denotes the random effect accounting for the individual difference from the typical value normally distributed with mean 0 and variance $\Omega$. Correlations between random effects were tested. The residual variability was tested with additive, proportional, and combined error models. The model was developed by comparing several structural models through evaluation of Akaike's information criteria (AIC), precision of the parameter estimates, physiological meaningfulness of parameter estimates, and visual assessment goodness-of-fit plots.

Covariates were analyzed in the model using formulation type (free, NCP80 or NCEUD) as categorical covariates. Covariates were included in the model according to both the likelihood ratio test (LRT, forward inclusion $p<$ 0.05 , backward elimination $p<0.01$ ) and the Wald test $(p<0.05)$. Improvements in the precision of parameter estimates and goodness of fit plots were also evaluated. Model stability was evaluated through visual predictive check (VPC) of 1000 scenarios.

\section{Antimalarial Efficacy in Plasmodium berghei-Infected Mice}

The evaluated treatments were saline, F-QN, NCP80, UNCP80, NCEUD, UNCEUD, and chloroquine (positive control, intraperitoneal route, $10 \mathrm{mg} / \mathrm{kg}$ ). The $\mathrm{QN}$ dose administered was $40 \mathrm{mg} / \mathrm{kg}$, divided into two administrations per day. Treatment started on day 0.5 (day of infection) and continued until day 3.5. After inoculation, the percentage of infected erythrocytes was determined in blood films fixed with methanol and stained with Giemsa solution to $10 \%$ to microscopically determine the percentage of parasitemia (oil immersion, $1000 \times$ magnification). The experiment followed Peter's suppression protocol ${ }^{30}$ and parasitemia was monitored until all animals had died. The survival time of animals was evaluated as well as the percentage of average parasitemia via blood smears and antimalarial activity.

\section{Statistical Analysis}

The results are expressed as mean \pm standard deviation (SD). One-way analysis of variance (ANOVA) followed by Tukey's test was used to compare mean values with GraphPad Prism 5 Software (GraphPad Software, USA). 
Differences among mean values were considered statistically significant when $\mathrm{p}<0.05$.

\section{Results and Discussion \\ Technological Evaluation of Quinine-Loaded Nanocapsules}

A series of nanoparticulate systems have been developed using different polymers and surfactants to propose formulations with specific surface characteristics. The aim was to obtain effective QN-loaded nanostructures targeted to biophase (infected RBCs). Nanoparticles with different surface characteristics and supramolecular organization were characterized by physicochemical parameters such as diameter $(\mathrm{nm})$, polydispersity, $\mathrm{pH}$, zeta potential $(\mathrm{mV})$, content $(\%)$, and rate of $\mathrm{QN}$ encapsulation (\%). Unloaded nanoparticles were prepared for comparison. All analyses were performed in triplicate and the results are shown in Table 1.

EUD was selected to cover the positive surface of the nanocapsules to promote greater electrostatic interaction between the drug and the sublingual ${ }^{31}$ and vaginal $^{32}$ mucosa, as epidermis membranes. ${ }^{33}$ The effect of cationic nanocapsules has been described by our research group, including the development of PCL- and EUD-loaded Curcuma oil, which have been evaluated as experimental malaria treatments. Similar results were obtained with both formulations. ${ }^{16}$ Considering the surface characteristics, polysorbate 80 (P80)-coated PCL nanocapsules have been demonstrated to lower the interfacial tension between the particle and the cell. ${ }^{14,34,35}$

Formulations were prepared from preformed polymers. Using the nanoprecipitation method, factors such as type and concentration of the polymer, surfactants and oil influence the particle size of the system. ${ }^{36}$

The presence of oil did not influence physical-chemical characteristics of systems. NC and NS presented diameters in the nanometric range. However, $\mathrm{NC}$ demonstrated better reproducibility, as shown by the smallest standard deviation, particularly for PCL-nanoparticles. This difficulty in the reproducibility of the NS diameter can be attributed to greater instability in the system during preparation. The absence of an oily nucleus modifies the solubility of drug in the matrix, changing the physical properties. ${ }^{37}$ Thus, differences in size were not observed between distinct systems prepared with the same polymer.

The diameters of unloaded and QN-loaded NCs were between 139 and $185 \mathrm{~nm}$, with SPAN below 2 and a low standard deviation, indicating homogeneity of the particles in nanosuspension. Incorporation of QN decreased the $\mathrm{NC}$ particle size, which was not observed for NS.

As shown, NCP80 presented a significantly greater mean diameter than NCEUD $(180 \pm 0.4$ versus $141 \pm 2.0$ $\mathrm{nm}$, respectively). Unloaded nanocapsules presented the same difference, consistent with the findings of Schaffazick et al and Gomes et al, who developed NC using the same polymers. Furthermore, similar particle sizes are reported ranging from 154 to $185 \mathrm{~nm}$ for NCs prepared with ERS. ${ }^{38,16}$

The $\mathrm{pH}$ of all QN-loaded nanoparticles was more basic than the respective blank-NC or blank-NS (Table 1). QN is a basic drug with a chemical structure similar to that of alkaloids. ${ }^{9}$ The $\mathrm{pH}$ values obtained for PCL nanoparticles were significantly lower than those obtained for the other suspensions. The higher acidity may be associated with ionization of the functional groups present on the polymer chains of PCL, for example, the terminal carboxylic groups, which are present in the polymer, lowering the pH. ${ }^{14,37,39}$

The PCL-nanoparticles presented negative zeta potentials, ranging from -19.7 to $-33.8 \mathrm{mV}$ (UNSP80 and NCP80, respectively). The negative charge is due to the PCL polymer and surfactant Lipoid S45 ${ }^{\circledR} \cdot 40,41$ The main

Table I Physico-Chemical Characterization of Unloaded and Quinine-Loaded Polymeric Nanocapsules and Nanospheres

\begin{tabular}{|l|l|l|l|l|l|l|l|l|}
\hline Parameter & NCP80 & UNCP80 & NSP80 & UNSP80 & NCEUD & UNCEUD & NSEUD & UNSEUD \\
\hline Diameter (nm) \pm SD & $180 \pm 0.4^{\mathrm{c}}$ & $184 \pm 1.0$ & $200 \pm 29.0$ & $201 \pm 23.0$ & $141 \pm 2.0^{\mathrm{c}}$ & $146 \pm 0.4$ & $138 \pm 3.8$ & $148 \pm 5.5$ \\
$\mathrm{pH} \pm \mathrm{SD}$ & $7.5 \pm 0.04^{\mathrm{c}}$ & $6.4 \pm 0.01$ & $7.2 \pm 0.02$ & $6.8 \pm 0.03$ & $8.3 \pm 0.02^{\mathrm{c}}$ & $7.1 \pm 0.13$ & $8.4 \pm 0.01$ & $7.7 \pm 0.02$ \\
Zeta potential (mV) \pm SD & $-33.1 \pm 0.7^{\mathrm{a}, \mathrm{c}}$ & $-30.5 \pm 1$ & $-25.5 \pm 1^{\mathrm{a}}$ & $-20 \pm 0.3$ & $4.61 \pm \mathrm{I}^{\mathrm{b}, \mathrm{c}}$ & $14.1 \pm 0.9$ & $2.86 \pm 0.3^{\mathrm{b}}$ & $2.84 \pm 0.6$ \\
Drug content (\%) $\pm \mathrm{SD}$ & $101.7 \pm 1.6^{\mathrm{a}}$ & - & $81.5 \pm 4.9^{\mathrm{a}}$ & & $102.9 \pm 1.1^{\mathrm{b}}$ & - & $89.5 \pm 4.9^{\mathrm{b}}$ & \\
EE $(\%) \pm \mathrm{SD}$ & $81.0 \pm 0.8^{\mathrm{a}, \mathrm{c}}$ & - & $72.4 \pm 3^{\mathrm{a}}$ & & $71.4 \pm 0.2^{\mathrm{bc}}$ & - & $41.6 \pm 3^{\mathrm{b}}$ & \\
\hline
\end{tabular}

Notes: ${ }^{\mathrm{a} S i g n i f i c a n t}$ difference between NCP80 and NSP80; ${ }^{\mathrm{b}}$ Significant difference between NCEUD and NSEUD; ${ }^{\mathrm{c}}$ Significant difference between NCP80 and NCEUD $(p>0.05$, ANOVA).

Abbreviations: SD, standard deviation $(n=3)$; NC, nanocapsules; NS, nanospheres; U, unloaded nanoparticles; P80, P80-coated nanoparticles prepared with PCL; EUD, nanoparticles Prepared with EUD. 
phospholipids in lecithin are phosphatidylcholine and phosphatidylethanolamine. Small amounts of lipids, such as phosphatidic acid, phosphatidylserine, and phosphatidylglycerol, may also be present. $^{42}$ These lipids are ionized at $\mathrm{pH} 7.0$ to induce a negative surface charge on nanoparticles, which contributes to their stability. ${ }^{43}$ The PCL polymer also influences the negative zeta potential of nanoparticles due to the presence of ester groups and the polymer, based on the values previously described for formulations prepared with this polymer ${ }^{34,39,44,45}$ and the influence of P80-coating, through the particle by steric stabilization. $^{46,47}$

In this study, PCL-NS presented a zeta potential less than that of PCL-NC, suggesting that capric/caprylic triglycerides also influence the zeta potential, since the organization of these nanostructures differs. The oily core used in this study comprised triglycerides of fractionated $\mathrm{C}_{8}$ and $\mathrm{C}_{10}$ plant fatty acids. To confirm the influence of oil on the zeta potential, we developed nanoemulsion (without polymer), which exhibited $-34.7 \pm 1$ and $-26.0 \pm 1 \mathrm{mV}$ for the QN and blank nanoemulsion, respectively. These results do not preclude the presence of droplets in the formulations of NCP80 and UNCP80.

As expected, nanoparticles based on EUD presented a positive zeta potential, which was attributed to the positively charged quaternary ammonium group present in the polymer EUD, which is consistent with previous results using the same polymer. ${ }^{16,48,49}$ The cationic zeta potential has an important role in the electrostatic interaction with the cell membrane, allowing a greater affinity between particle-membrane and, consequently, improved biological performance. $^{22,50}$

Drug loading was almost $100 \%$ for all NCs (100.1-104.1\%). This was not observed for NS, which had a recovery of around $80 \%(81.5 \pm 4.9 \%$ for NSP80 and $89.6 \pm$ $4 \%$ for NCEUD). This may be due to the difficulty of the preparation and the reproducibility of the results, since the absence of oil in the composition caused the precipitation of polymer, which may have resulted in the loss of some of the drug. Additionally, the solubility of drug in the oily core is fundamental for drug nanoencapsulation. ${ }^{51-53}$

The encapsulation rate was higher for NCP80 and NSP80 ( $81 \pm 0.8$ and $72.4 \pm 3 \%$, respectively) followed by NCEUD $(71.4 \pm 0.2 \%)$. The encapsulation rate is related to the solubility of the drug in oil, ${ }^{51}$ i.e. the lipophilicity of the substance, and the QN has a high $\log \mathrm{P}(\log \mathrm{P}=3.44)$, confirming the affinity of QN for the oily nucleus. Our results showed that anionic nanocapsules prepared with PCL encapsulate high concentrations of $\mathrm{QN}$, despite the high concentration of drug used in the formulation $(2 \mathrm{mg} / \mathrm{mL}) .^{14}$

Considering the lability of $\mathrm{QN}^{54,55}$ and the protection conferred by nanoencapsulation to several drugs, we evaluated the influence of surface characteristics and the type of nanostructure on QN photoprotection. For this, we monitored dark reactions following UV-Vis light exposure. The photosensitivity of QN was verified from forced degradation studies at $352 \mathrm{~nm}$. The results of the kinetic parameters are shown in Table 2. After $8 \mathrm{~h}$ exposure, free QN presented approximately $70 \%$ of the drug, while all formulations significantly $(p<0.05)$ protected QN from photodegradation, reducing degradation two- to threefold. Protection against UVA radiation was higher for NCP80 than for others, showing that the polymer and the type of structure determine the degree of photoprotection.

$\mathrm{NC}$ offered significantly greater protection than NS $(p<0.05)(9.9 \pm 0.4,12.4 \pm 0.91,13.3 \pm 0.6$, and $15.6 \pm$ $0.69 \%$ for NCP80, NSP80, NCEUD, and NSEUD, respectively). NS presented the shortest $t_{1 / 2}$ for degradation, which was approximately tenfold lower than that of the NCs with the same polymers. Additionally, $t_{1 / 2}$ increased approximately by $30 \%$ for NCP80, whereas a twofold increase was observed for NCEUD compared to that of Free QN. Both NCs showed zero order (MSC > 4.0, $\mathrm{R}>0.98)$, characterizing slow degradation.

Table 2 Mathematical Modeling of QN Photodegradation Profiles

\begin{tabular}{|l|l|l|l|l|l|l|}
\hline Sample & Reaction Order & $\boldsymbol{R}$ & $\mathbf{M S C}$ & $\mathbf{K}_{\left(\mathbf{h}^{-\mathbf{l}}\right)}$ & $\mathbf{T}_{\mathbf{1} / \mathbf{2}}(\mathbf{h}) \pm \mathbf{S D}$ & Photodegradation (\%) \pm SD \\
\hline Free QN & Bioexponential & 0.9822 & 3.2 & 0.00037 & $1754 \pm 37$ & $27.1 \pm 0.2$ \\
NCP80 & Zero & 0.9830 & 4.3 & 0.0002 & $2413 \pm 13^{\mathrm{a}, \mathrm{b}, \mathrm{d}}$ & $9.9 \pm 0.4^{\mathrm{a}, \mathrm{b}, \mathrm{d}}$ \\
NSP80 & Bioexponential & 0.9834 & 4.1 & 0.002 & $299 \pm 13^{\mathrm{a}, \mathrm{b}}$ & $12.4 \pm 0.9^{\mathrm{a}, \mathrm{b}}$ \\
NCEUD & Zero & 0.9940 & 4.7 & 0.0001 & $3450 \pm 16^{\mathrm{a}, \mathrm{d}}$ & $13.3 \pm 0.6^{\mathrm{a}, \mathrm{c}, \mathrm{d}}$ \\
NSEUD & Monoexponential & 0.9968 & 4.0 & 0.002 & $343 \pm 22^{\mathrm{a}}$ & $15.7 \pm 0.6^{\mathrm{a}, \mathrm{c}}$ \\
\hline
\end{tabular}

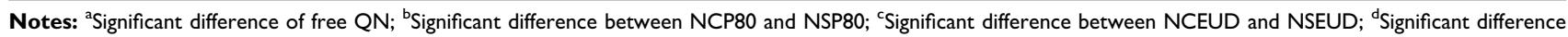
between NCP80 and NCEUD ( $p>0.05$, ANOVA).

Abbreviations: SD, standard deviation $(n=3)$; R, correlation coefficient; MSC, model selection criteria; $K$, constant for the reaction speed; $T_{1 / 2}$, half-life time degradation. 
The structure and polymer of the nanoparticles influenced the photodegradation and release profile of QN. The NC presents two diffusion barriers to drug release: the polymer wall and the oily core. The polymer wall prevents direct contact of the drug with the tissue, which is dissolved in the oil core, helping in preventing immediate release of the drug ${ }^{56,57}$ causing a lower percentage breakdown than that with NS. Recently, P80-coated PCL-nanocapsules were shown to protect dithranbol, ${ }^{58}$ indole-3-carbinol, ${ }^{59}$ Coenzyme Q10, ${ }^{60}$ quinine $^{26}$ and betamethasone dipropionate. ${ }^{45}$ Furthermore, clotrimazole, acetazolamide, and quinine have been reported to demonstrate protection conferred by EUD. ${ }^{26,48,61}$

\section{Quinine Partition Coefficient in Erythrocytes}

The QN partition coefficient in erythrocytes $(D)$ was determined to assess the ability of the coating (anionic/cationic) or supramolecular structure (NC/NS) to increase QN binding to erythrocytes. The partition coefficient of the F-QN-infected erythrocytes was $3.74 \pm 0.02$, a result similar to that obtained previously by Haas et $\mathrm{al}^{14}$ using Epikuron 170 (egg yolk lecithin with approximately $70 \%$ phosphatidylcholine). The NCP80 showed the highest $D(8.92 \pm 0.7)$, which was statistically higher than that of NCEUD $(6.48 \pm 0.08)$. Values of 4.86 \pm 0.49 and $3.75 \pm 0.04$ were observed for NSP80 and NSEUD, respectively. Regardless of the type of coating, all coated-NCs presented higher $D$ values than NS, presenting a significant difference in relation to free QN. Therefore, nanoencapsulation doubled the $D$ compared with QN in infected erythrocytes, suggesting a possible improvement in the effectiveness of QN following nanoencapsulation. These results demonstrate that coated-NCs feature the best structure in terms of the capacity to carry QN into the infected erythrocytes.

The interactions between NC and cells have often been studied, and some hypotheses have been considered. When parasitized, changes occur in the cell membrane of erythrocytes, including modification of transport properties, exposure of surface antigens, and morphology, characterized by the formation of protrusions, until the rupture of the erythrocyte. ${ }^{62}$ This may facilitate the adhesion of nanoparticles to infected erythrocytes, providing greater contact between QN and the parasite in cell vacuoles.

\section{Atomic Force Microscopy}

Nanocapsules demonstrated improved reproducibility, monodispersity, high drug content, encapsulation rate, QN protection against UVA light, and higher $D$. For these reasons, evaluation of morphology by atomic force microscopy (AFM) and biological assessments were performed only with the NCP80, NCEUD, and their blank formulations. Particles presented regular spherical structures and sizes (Figure 1), which is consistent with the results obtained by analysis of polydispersion index $($ SPAN $<2)$. The average size of the nanoparticles, determined by analyzing the MFA in the nanometer range (about $220 \mathrm{~nm}$ to NCP80 and $180 \mathrm{~nm}$ for the NCEUD), was consistent with the results obtained by laser diffraction using a Mastersizer ${ }^{\circledR} 2000$. Although the diameter of the unloaded nanocapsules was higher when analyzed by MFA (about $400 \mathrm{~nm}$ for UNCP80 and $470 \mathrm{~nm}$ for UNCEUD) compared with that when analyzed by diffraction laser (Table 1), they were homogenous and spherical, even within a nanometer diameter range (Figure 1B-D).

\section{Non-Compartmental and compartmental Analyses of Plasma Data}

Pharmacokinetic studies were performed to assess whether nanoparticulate systems with modified surface characteristics alter the pharmacokinetic profile of QN. The mean pharmacokinetic parameters determined by NCA for QN in rats $(20 \mathrm{mg} / \mathrm{kg}$, i.v. route) are summarized in Table 3 . The two-compartmental model showed good agreement with NCA parameters.

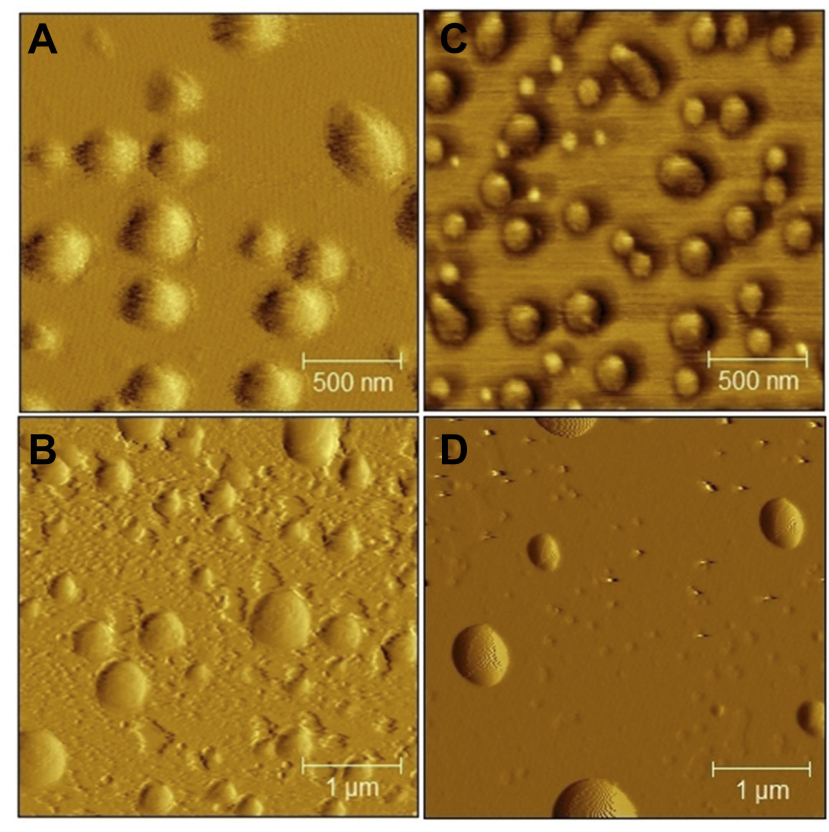

Figure I Images obtained by the AFM for NCP80 (A), UNCP80 (B), NCEUD (C), and UNCEUD (D). 
Table 3 QN Pharmacokinetic Parameters in Plasma After 20 mg/kg i.v. Bolus Dosing to Plasmodium berghei-Infected Rats

\begin{tabular}{|c|c|c|c|c|c|c|}
\hline \multirow[t]{2}{*}{ PK Parameters } & \multicolumn{3}{|c|}{ Non-Compartmental } & \multicolumn{3}{|c|}{ Two-Compartmental Model } \\
\hline & Free $(n=5)$ & $\operatorname{NCP80}(n=4)$ & NCEUD $(n=6)$ & Free $(n=5)$ & NCP80 $(n=4)$ & NCEUD $(n=6)$ \\
\hline $\mathrm{AUC}_{0-\mathrm{t}}(\mu \mathrm{g} . \mathrm{h} / \mathrm{mL})$ & $32.4 \pm 5.0$ & $55.9 \pm 41.1$ & $58.8 \pm 21.0$ & - & - & - \\
\hline$A \cup C_{0-\infty}(\mu g . h / m L)$ & $33.8 \pm 4.8$ & $61.1 \pm 41.2$ & $59.8 \pm 22.2$ & 32.13 & 30.54 & 55.13 \\
\hline $\mathrm{AUMC}_{0-\mathrm{t}}\left(\mu \mathrm{g} \cdot \mathrm{h}^{2} / \mathrm{mL}\right)$ & $67.7 \pm 12.5$ & $156.4 \pm 65.7^{\mathrm{a}}$ & $73.6 \pm 41.3$ & - & - & - \\
\hline $\mathrm{CL}_{\text {Tot }}(\mathrm{L} / \mathrm{h})$ & $0.09 \pm 0.01$ & $0.08 \pm 0.05$ & $0.06 \pm 0.02$ & 0.09 & 0.10 & 0.06 \\
\hline$t_{1 / 2}(h)$ & $1.68 \pm 0.33$ & $16.14 \pm|3.2|^{\mathrm{a}}$ & $7.11 \pm 3.90^{\mathrm{a}}$ & 1.76 & 10.06 & 4.87 \\
\hline $\operatorname{Ke}\left(\mathrm{h}^{-1}\right)$ or $\beta\left(\mathrm{h}^{-1}\right)$ & $0.43 \pm 0.09$ & $0.07 \pm 0.04^{\mathrm{a}, \mathrm{b}}$ & $0.14 \pm 0.10^{\mathrm{a}, \mathrm{b}}$ & 0.39 & 0.06 & 0.14 \\
\hline MRT $\left(\mathrm{h}^{-1}\right)$ & $2.10 \pm 0.47$ & $6.20 \pm 2.46^{\mathrm{a}, \mathrm{b}}$ & $1.48 \pm 0.62^{\mathrm{b}}$ & - & - & - \\
\hline Vdss (mL/kg) & $0.198 \pm 0.070$ & $0.570 \pm 0.418^{\mathrm{a}, \mathrm{b}}$ & $0.077 \pm 0.01 I^{a, b}$ & 0.183 & 0.502 & 0.06 \\
\hline
\end{tabular}

Notes: ${ }^{a}$ Significant difference of free QN; ${ }^{b}$ Significant difference between NCP80 and NCEUD ( $p<0.05$, ANOVA).

Abbreviations: $\mathrm{Ke}$, elimination rate constant; $\mathrm{t}_{\mathrm{I} / 2}$, half-life; $A U \mathrm{C}_{0-\infty}$, area under the curve; $M R T$, mean residence time; $\mathrm{CL}_{\text {total }}$, total plasma clearance; $\mathrm{V} \mathrm{d}_{\mathrm{ss}}$, volume of distribution at steady state.

Attempts to prolong the intravascular circulation times of polymeric nanoparticles have primarily focused on surface modification. The use of surface coatings primarily aimed at providing a repulsive steric barrier, preventing the flocculation of particles and decreasing opsonization, and the adsorption of biological components. ${ }^{63}$ Plasma concentrations of the free drug (Figure 2) were only quantified up to $8 \mathrm{~h}$, unlike nanoencapsulated-QN (NCP80 and NCEUD), which were quantified for $24 \mathrm{~h}$, demonstrating the increased drug circulation time through the incorporation of nanoparticulate systems, since their release into the blood occurs slowly. ${ }^{12,22,64}$ The extrapolated AUC was less than $20 \%$ for all groups.

In fact, $t_{1 / 2}$ significantly increased following nanoencapsulation by different magnitudes, demonstrating that the reservoir system and surface characteristics influence the plasma pharmacokinetics of QN. The $t_{1 / 2}$ of NCP80 was higher than that of the free drug (16.14 versus $1.68 \mathrm{~h}$, media, respectively) as a result of the twofold increase in Vdss with P80 coating of QN loaded-nanocapsules (0.198 $\pm 0.070-0.570 \pm 0.418 \mathrm{~mL} / \mathrm{kg}$ ) (Table 3). Cationic nanocapsules presented a significant reduction in the Vdss of QN. After nanoencapsulation, Vdss values up to $0.077 \pm$ $0.011 \mathrm{~mL} / \mathrm{kg}$ were observed and $\mathrm{t}_{1 / 2}$ increased fourfold in relation to free QN. Thus, all formulations modified the distribution parameter in opposite directions. A population pharmacokinetic approach was used to evaluate other pharmacokinetic changes caused by nanoencapsulation.

\section{Population Pharmacokinetic Model Development}

A two-compartment model with first-order elimination and combined residual error models for total concentrations of
QN was selected as the final model for all groups. The system of differential equations for the final model is given in Equation (3a) to (3c).

$$
\begin{gathered}
\frac{d X c_{1}}{d t}=\left(\frac{Q}{V_{2}} \times X_{C_{2}}\right)-\left(\frac{Q}{V_{1}} \times X_{C_{1}}\right)-\left(\frac{C l}{V_{1}} \times X_{C_{1}}\right) \\
\frac{d X_{C_{2}}}{d t}=\left(\frac{Q}{V_{1}} \times X_{C_{1}}\right)-\left(\frac{Q}{V_{2}} \times X_{C_{2}}\right) \\
\frac{d E}{d t}=\frac{C l}{V_{1}} \times X_{C_{1}}
\end{gathered}
$$

where $\mathrm{Xc}_{1}$ and $\mathrm{Xc}_{2}$ are the drug concentrations in the central and peripheral compartments, respectively; $V_{1}$ represents the volume of the central compartment; $V_{2}$ is the volume of distribution in the peripheral compartment; $\mathrm{Q}$ is the intercompartmental clearance; $\mathrm{Cl}$ is the clearance; $\mathrm{E}$ is the amount of drug eliminated and $\mathrm{t}$ is the time.

The estimated parameter values are presented in Table 4. All parameters were well estimated with low relative standard errors (RSE). The inter-individual variability was retained for all PK parameters. Based on goodness-of-fit plots and lower AIC, the proportional model was the best residual error model for total plasma (Figure 2).

Covariate analysis showed that nanoformulations strongly and significantly influenced on intercompartmental clearance (Q) with significant $\mathrm{p}$ values, such as $\mathrm{p}=0.00194$ (NCP80) and $\mathrm{p}=1.02 \mathrm{e}^{-10}$ (NCEUD) calculated after Wald Test. Additionally, the compartmental volume of distribution (V2) was influenced by the NCP80 ( $\mathrm{p}=0.00197$, Wald test), while the V1 was negatively modified by NCEUD.

Equations (4) and (5) describe the categorical covariate model. 

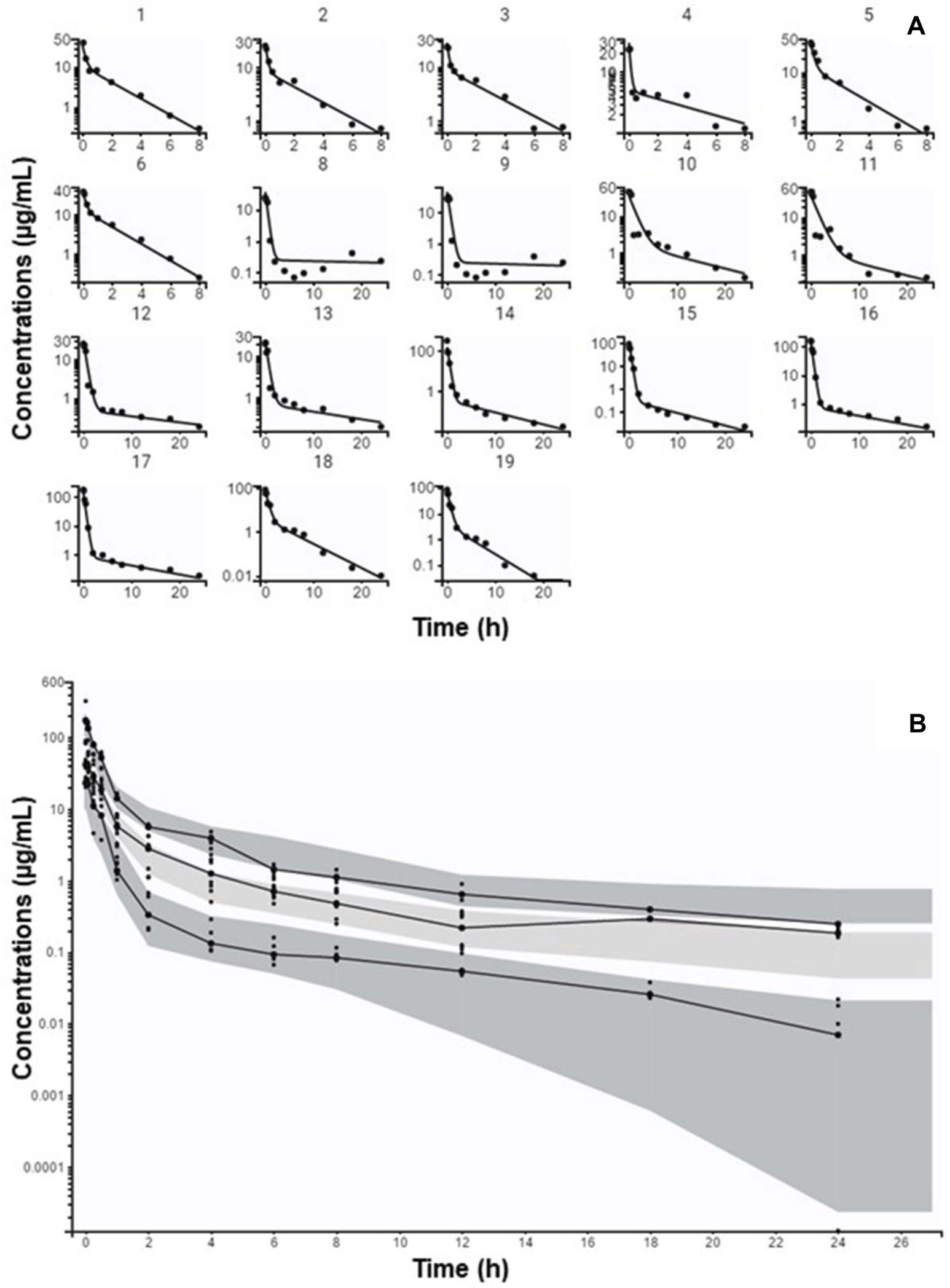

Figure 2 (A) POP pk fit mean ( \pm standard deviation) plasma-time profiles of free quinine, NCP80, and NCEUD after a single $20 \mathrm{mg} / \mathrm{kg}$ intravenous dose in Wistar rats infected with $P$. berghei. (B) Visual predictive check. 
Table 4 Parameter Estimates of the Final Quinine Population Pharmacokinetic Model

\begin{tabular}{|c|c|c|c|c|}
\hline Parameter & Estimate & $\begin{array}{l}\text { RSE } \\
(\%)\end{array}$ & $\begin{array}{l}\text { Interindividual } \\
\text { Variability }\end{array}$ & $\begin{array}{l}\text { RSE } \\
\text { (\%) }\end{array}$ \\
\hline VI (L) & 0.611 & 18.4 & 0.268 & 30.6 \\
\hline$\beta \_V I \_C A T_{\text {NCEUD }}$ & -1.29 & 18 & NA & NA \\
\hline CL (L/h) & 0.453 & 9.01 & 0.330 & 20.7 \\
\hline $\mathbf{Q}_{\text {pop }}$ & 1.98 & 44.1 & 0.751 & 20.4 \\
\hline B_Q_CAT ${ }_{\text {NCP80 }}$ & -1.71 & 32.3 & NA & NA \\
\hline$\beta \_Q_{-} C A T_{\text {NCEUD }}$ & -3.59 & 15.5 & NA & NA \\
\hline V2 pop & 0.956 & 42 & 0.965 & 19.3 \\
\hline B_V2_NCP80 & 1.91 & 32.3 & NA & NA \\
\hline $\mathbf{K}_{12 \_ \text {pop }}\left(\mathbf{h}^{-1}\right) *$ & 3.24 & & & \\
\hline$K_{12 \_N C P 80}\left(h^{-1}\right)$ & 0.58 & & & \\
\hline $\mathrm{K}_{12 \text { NCEUD }}\left(\mathrm{h}^{-1}\right)$ & 0.324 & & & \\
\hline $\mathbf{K}_{21 \_p o p}\left(\mathbf{h}^{-1}\right) *$ & 2.07 & & & \\
\hline $\mathrm{K}_{21 \_N C P 80}\left(\mathrm{~h}^{-1}\right)$ & 0.055 & & & \\
\hline K21_NCEUD $\left(\mathrm{h}^{-1}\right)$ & 0.056 & & & \\
\hline \multicolumn{5}{|l|}{ Residual variability } \\
\hline Proportional model & 0.39 & 6.08 & & \\
\hline $\begin{array}{l}\text { log-likelihood } \\
\text { estimate }\end{array}$ & 692.98 & & & \\
\hline AIC & 728.98 & & & \\
\hline
\end{tabular}

Abbreviations: NA, not applicable; RSE, relative standard error (standard error of estimate/estimate $\times 100$ ); VI, central volume compartment; V2, peripheral compartment volume; $\mathrm{Q}$, intercompartmental clearance.

$$
\begin{gathered}
Q_{, p o p, Q}=Q_{p o p, Q} * . e^{\beta_{-} Q \_N C} \\
V_{2, p o p, V}=V_{2 p o p, V} * . e^{\beta_{-} V_{2}-N C}
\end{gathered}
$$

where $\mathrm{Q}_{\text {,pop, } \mathrm{Q}}$ and $\mathrm{V}_{2, \mathrm{pop}, \mathrm{V}^{*}}$ represent the intercompartmental Clearance and intercompartmental volume of distribution, respectively; overall, there was a good agreement for the predicted and observed concentrations of total plasma concentrations between all groups (Figure 2A and B).

QN compartmental parameters $(\mathrm{Q}, \mathrm{V} 1$, and $\mathrm{V} 2)$ were altered by the drug targeting. Distribution was increased after NCP80 administration $(6.46 \mathrm{~L} / \mathrm{Kg})$ instead of NCEUD decreased V2 $(0.17 \mathrm{~L} / \mathrm{Kg})$ in relation to the population corroborating the NCA analysis (Table 3). The parameters for the covariates were calculated from the population values using $\beta$. For $\mathrm{Q}$, the two formulations act as covariates.

Distribution microconstants calculated from the values of Q, V1 and V2 showed significant differences in relation to the populational parameters. NCP80 showed that the $\mathrm{K}_{12}$ is about 10 times higher than $\mathrm{K}_{21}$ demonstrating that the return of the QN to the circulation is delayed. In addition, Q was shown to be inferior to the control
(0.033 versus $0.278 \mathrm{~L} / \mathrm{h}$, respectively, for NCP80 and $\mathrm{QN})$, resulting in a tenfold increase in the $\mathrm{t}^{1} / 2$ of $\mathrm{QN}$.

Distribution microconstants calculated from beta values revealed significant differences in relation to the populational parameters. NCEUD presented reduced K12 values $(0.19$, 0.67 and $2.0 \mathrm{~h}^{-1}$ for populational, NCP80, and NCEUD, respectively) with the slow transfer of QN into the tissues, probably the RBCs. Conversely, NCP80 indicated that the return of QN to the circulation was delayed (beta -3.15 ), consistent with its prolonged $t_{1 / 2}$.

Nanoencapsulation can significantly modify drug distribution and exposure. Population analyses can be effectively utilized to characterize any such differences with appropriate data. The current analyses revealed that formulation impacted the peripherical distribution and clearance. The surface charge of nanoparticles is critical because it influences blood flow and interactions with the cell membrane. ${ }^{65,66}$ Blood cells carry a negative charge, and particles with a similar charge tend to be repelled, minimizing the interaction. Conversely, the cationic surface of NCEUD may have caused quinine to adhere more closely to blood components by lowering V2 and $\mathrm{K}_{12}$.

Malaria parasites frequently develop resistance to quinine due to administration of the drug at low concentrations in the presence of a high parasitic load. ${ }^{67} \mathrm{NCP} 80$ and NCEUD have the potential to increase the intra-erythrocyte concentration of QN (as shown above), and were able to improve the in vivo biodistribution of QN. In addition, nanocarrier systems for antimalarial drugs should remain in the systemic circulation for a long duration to enhance the interaction of drugs with infected erythrocytes and parasite membranes. This advantage is particularly important for malaria therapy, since the development of new dosage forms for the delivery of drugs to parasite-infected cells is urgently needed, especially for the antimalarials currently in clinical use.

\section{Antimalarial Efficacy of QN in Plasmodium berghei-Infected Mice}

The present study was performed by administering $40 \mathrm{mg} / \mathrm{Kg}$ (twice a day $20 \mathrm{mg} / \mathrm{Kg}, \mathrm{D} 0.5-\mathrm{D} 3.5$ ) of free- and nanoencapsulated-QN. Saline and blank formulations were used as negative controls and chloroquine $(10 \mathrm{mg} / \mathrm{kg})$ was used as a positive control. The survival time of animals treated with free QN and saline was $13 \pm 1.8$ and $10.3 \pm 1.0$ days, respectively $(p>0.05)$. There was a significant increase in the survival of animals treated with NC-QN compared to that of animals treated with saline (13.8 \pm 1.1 for NCP80 and $19.5 \pm$ 1.9 days for NCEUD). NCEUD increased survival by around 
Table 5 Efficacy of Different Treatments in Swiss Mice Experimentally Infected with Plasmodium Berghei

\begin{tabular}{|l|l|l|l|l|l|}
\hline \multirow{2}{*}{ Groups } & \multicolumn{2}{|l|}{ Survival (Days) } & \multicolumn{2}{l|}{$\begin{array}{l}\text { Parasitemia } \\
\text { (\%) }\end{array}$} & $\begin{array}{l}\text { Supression } \\
\text { (\%) }\end{array}$ \\
\cline { 2 - 5 } & Mean & SD & Mean & SD & \\
\hline Saline & 10.3 & $1.0^{\mathrm{c}, \mathrm{d}}$ & 5.7 & $2.0^{\mathrm{d}}$ & - \\
Free QN & 13.0 & $1.8^{\mathrm{a}, \mathrm{c}, \mathrm{d}}$ & 3.5 & $0.3^{\mathrm{d}}$ & 41 \\
NCP80 & 13.8 & $1.1^{\mathrm{a}, \mathrm{d}}$ & 4.5 & $2.8^{\mathrm{d}}$ & 46 \\
UNCP80 & 8.7 & $3.4^{\mathrm{d}}$ & 6.2 & $3.6^{\mathrm{d}}$ & 19 \\
NCEUD & 19.5 & $1.9^{\mathrm{a}, \mathrm{b}, \mathrm{c}}$ & 2.9 & $0.2^{\mathrm{a}, \mathrm{c}}$ & 59 \\
UNCEUD & 11.7 & $3.0^{\mathrm{d}}$ & 5.1 & $2.1^{\mathrm{d}}$ & 26 \\
Chloroquine & 19.7 & $1.6^{\mathrm{a}, \mathrm{c}}$ & 0.4 & $0.5^{\mathrm{a}, \mathrm{c}}$ & 88 \\
\hline
\end{tabular}

Notes: ${ }^{a}$ Significant difference versus saline; ${ }^{\mathrm{b}}$ Significant difference of free $\mathrm{QN}$; 'Significant difference between NCP80 and NCEUD ( $p<0.05$, ANOVA); 'Significant difference versus chloroquine.

Abbreviation: SD, standard deviation $(n=6)$.

9 days compared to that in the saline group, which was almost doubled, and by about 6-7 days compared to that of the group receiving free-QN (Table 5). Survival (in days) with NCEUD was similar to that observed with chloroquine.

Chloroquine was selected as a positive control due to its high efficacy in the treatment of malaria, and the suppressive efficacy was $88 \%$. Suppression of the malaria parasite was evaluated by comparing the percentage reduction of parasitemia between the treated and untreated groups. $^{31}$ Animals treated whit NCEUD, NCP80, and free QN showed 59\%, 46\%, and 41\% suppression, respectively. After 21 days post-infection, all animals treated with chloroquine (six of six) and NCEUD (three of six) survived.

The percentage of parasitemia was reduced in all drugtreated animals. However, the only NC able to significantly reduce parasitemia was NCEUD (mean parasitemia of $2.9 \pm$ $0.2 \%$ ), which demonstrated rapid action by controlling the levels of parasitemia at the start of treatment (Figure 3). The survival time of animals treated with UNC was shorter $(8.7 \pm$ 3.4 and $11.7 \pm 3.0$ days for UNCP80 and UNCEUD, respectively) than that of animals treated with loaded-NC. Excipients and unloaded nanocapsules did not demonstrate any antimalarial activity. In a previous study, QN formulated into polymeric nanocapsules with Epikuron $170^{\circledR}$ demonstrated effective antimalarial activity against $P$. berghei infection in rats with a $30 \%$ lower dose than used conventionally. ${ }^{14}$

NCEUD administered at $40 \mathrm{mg} / \mathrm{kg} /$ day by i.p. (intraperitoneal) route significantly increased survival compared to the same dose of free drug. In addition, the same formulation was associated with the lowest level of parasitemia among the NC evaluated, as well as the highest suppression of parasitemia (59\%). Recently, our group showed that QNloaded nanocapsules with Curcuma oil as the core led to $51 \%$ and $60 \%$ suppression, respectively, with anionic (PCL polymer) and cationic (prepared with EUD) properties in the same model. ${ }^{16}$ However, the survival time and level of parasitemia were similar. NCEUD acted as a covariate to V1 (Table 4) and markedly changed the values of $Q$ and $\mathrm{K}_{12}$, probably contributing to the observed results. In the

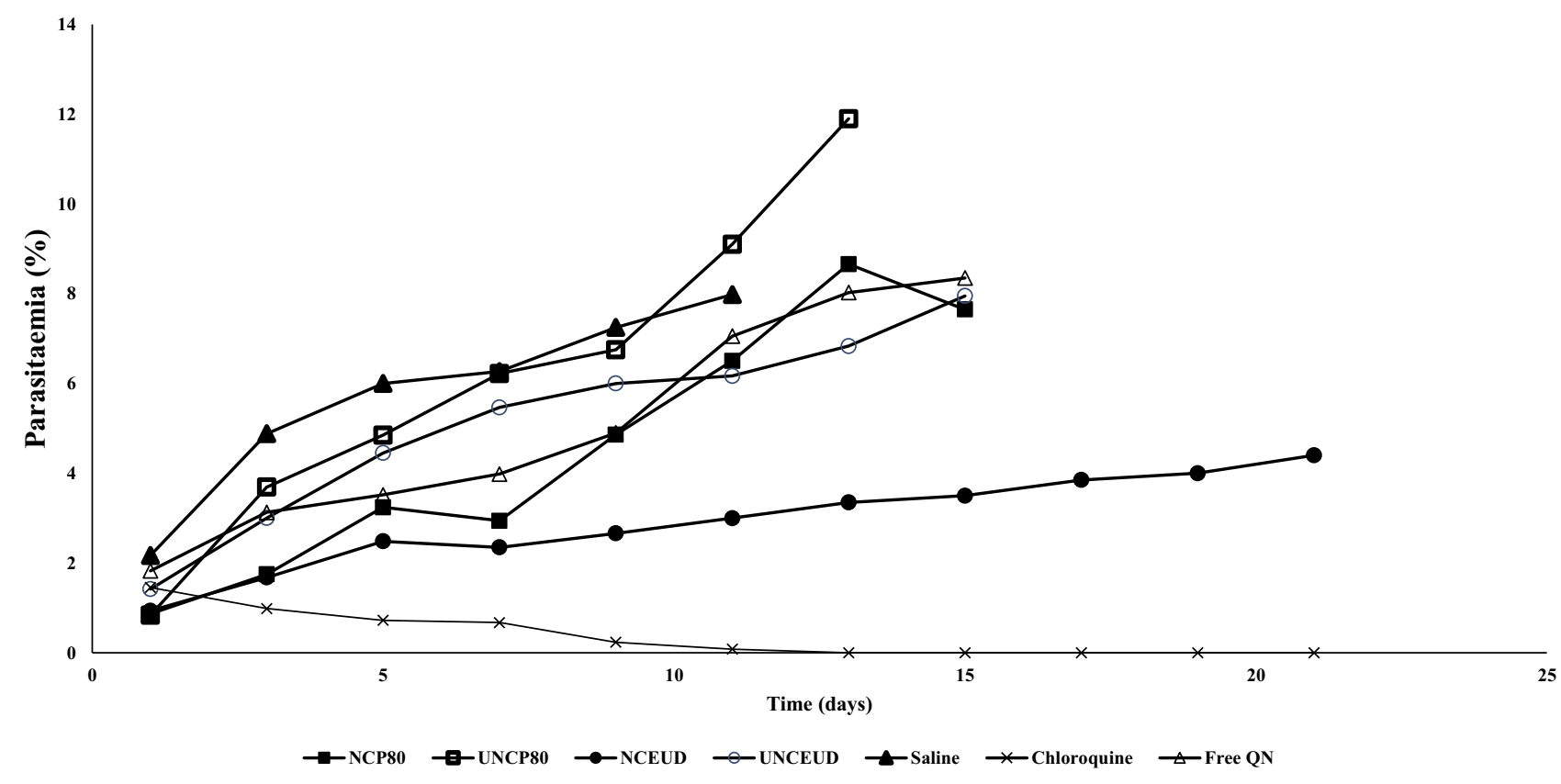

Figure 3 Profile of Parasitemia for evaluation of the antimalarial efficacy of the groups in P. berghei-infected Wistar rats $(n=6$ per group). 
in vitro test (partition coefficient into erythrocytes), it may be appropriate to evaluate the influence of nanoencapsulation on drugs, but not the magnitude of the difference between formulations with different coating characteristics. The cationic nanoparticle may have altered the efficacy of QN through increased electrostatic interaction with the negative erythrocyte membrane. Adherence of cationicEUD nanocapsules in the mucosa and biological surfaces has previously been shown. ${ }^{23,68}$ Consequently, the use of positively charged nanocapsules can lead to close contact between nanoparticles and infected erythrocytes, altering the biodistribution and efficacy of antimalarial drugs.

The findings of this study are consistent with previous findings, wherein the efficacy of antimalarials incorporated into nanoparticulate systems significantly increased the antimalarial efficacy unlike the free drug. This is probably because the nanocarriers are associated with higher intracellular uptake ${ }^{69}$ due to their increased surface area when the drug is nanoencapsulated, permitting a strong surface interaction. $^{31,70}$ Although anionic nanocapsules enhance the effectiveness of $\mathrm{QN}$, these results showed that the results obtained with NCEUD were the most satisfactory.

\section{Conclusion}

Cationic and anionic polymeric nanocapsules were developed to target QN to erythrocytes. Modulation of the nanosurface properties showed that QN is protected against UVA light, improved the QN partition coefficient into P. bergheiinfected erythrocytes in vitro, and increased the plasmatic QN half-life time of elimination in P. berghei infected rats. Furthermore, the biodistribution was modified and the NCEUD-induced reduction of $\mathrm{V} 1, \mathrm{Q}$, and $\mathrm{K} 12$ changed populational pharmacokinetic parameters. Subsequently, improved antiplasmodial efficacy was observed when cationic nanocapsules were prepared using EUD. Together, these results indicate the potential of polymeric nanocapsules to improve the antimalarial efficacy of drugs by the positive surface of carriers.

\section{Acknowledgments}

The authors are grateful for the support of the Rio Grande do Sul Science Foundation (FAPERGS), grants \#16/25510000207-0 and \#2083-2551/13-3, National Council of Technological and Scientific Development (CNPq) (Universal grant \# 423435/2016-7) and for student's scholarships. S.E Haas, L.R. Michels, and T.R. Maciel are recipients of CNPq, CAPES, and FAPERGS fellowships, respectively. This study was financed in part by the Coordenação de Aperfeiçoamento de Pessoal de Nível Superior - Brasil (CAPES) - Finance Code 001 .

\section{Disclosure}

The authors report no conflicts of interest in this work.

\section{References}

1. WHO. World Malaria Report 2018. Geneva: World Health Organization;2018. ISBN 9789241564403.

2. Basu S, Sahi PK. Malaria: an update. Indian J Pediatr. 2017. doi:10.1007/s12098-017-2332-2

3. Phillips A, Bassett P, Zeki S, Newman S, Pasvol G. Risk factors for severe disease in adults with falciparum malaria. Clin Infect Dis. 2009;48(7):871-878. doi:10.1086/597258

4. Aditya NP, Vathsala PG, Vieira V, Murthy RSR, Souto EB. Advances in nanomedicines for malaria treatment. Adv Colloid Interface Sci. 2013;201-202:1-17. doi:10.1016/j.cis.2013.10.014

5. Sinha S, Medhi B, Sehgal R. Challenges of drug-resistant malaria. Parasite. 2014;21:61. doi:10.1051/parasite/2014059

6. Fairhurst RM, Dondorp AM. Artemisinin-resistant Plasmodium falciparum malaria. Microbiol Spectr. 2016;4(3):El10-0013-2016. doi:10.1128/microbiolspec.EI10-0013-2016.Artemisinin-resistant

7. White NJ. Cardiotoxicity of antimalarial drugs. Lancet Infect Dis. 2007;7(8):549-558. doi:10.1016/S1473-3099(07)70187-1

8. Vale N, Moreira R, Gomes PA. Quimioterapia da Malária. 2004:57-69.

9. Achan J, Talisuna AO, Erhart A, et al. Quinine, an old anti-malarial drug in a modern world: role in the treatment of malaria. Malar $J$. 2011;10(1):144. doi:10.1186/1475-2875-10-144

10. Oyeyemi O, Morenkeji O, Afolayan F, et al. Curcumin-artesunate based polymeric nanoparticle; Antiplasmodial and toxicological evaluation in murine model. Front Pharmacol. 2018;9(MAY):1-8. doi:10.3389/fphar.2018.00562

11. Dauda K, Busari Z, Morenikeji O, Afolayan F. Poly (D, L -lactic- co -glycolic acid) -based artesunate nanoparticles : formulation, antimalarial and toxicity assessments. J Biomed Biotechnol. 2017;18 (11):977-985.

12. Mosqueira VCF, Loiseau PM, Legrand P, Devissaguet J, Bories C, Barratt G. Efficacy and pharmacokinetics of intravenous nanocapsule formulations of halofantrine in plasmodium berghei -infected mice efficacy and pharmacokinetics of intravenous nanocapsule formulations of halofantrine in Plasmodium berghei -infected mice. Antimicrob Agents Chemother. 2004;48(4):1222-1228. doi:10.1128/ AAC. 48.4 .1222

13. Santos-Magalhães NS, Mosqueira VCF. Nanotechnology applied to the treatment of malaria. Adv Drug Deliv Rev. 2010;62(4-5):560-575. doi:10.1016/j.addr.2009.11.024

14. Haas SE, Bettoni CC, de Oliveira LK, Guterres SS, Dalla Costa T. Nanoencapsulation increases quinine antimalarial efficacy against Plasmodium berghei in vivo. Int $J$ Antimicrob Agents. 2009;34 (2):156-161. doi:10.1016/j.ijantimicag.2009.02.024

15. Velasques K, Maciel TR, de Castro Dal Forno AH, et al. Conanoencapsulation of antimalarial drugs increases their in vitro efficacy against Plasmodium falciparum and decreases their toxicity to Caenorhabditis elegans. Eur J Pharm Sci. 2018;118:1-12. doi:10.1016/j.ejps.2018.03.014

16. Gomes GS, Maciel TR, Piegas EM, et al. Optimization of Curcuma oil/quinine-loaded nanocapsules for malaria treatment. AAPS PharmSciTech. 2017;(8). doi:10.1208/s12249-017-0854-6

17. Izaguirry AP, Pavin NF, Soares MB, et al. Effect of quinine-loaded polysorbate-coated nanocapsules on male and female reproductive systems of rats. Toxicol Res. 2016;5(6):1561-1572. doi:10.1039/ C6TX00203J 
18. Siafaka PI, Üstündağ Okur N, Karavas E, Bikiaris DN. Surface modified multifunctional and stimuli responsive nanoparticles for drug targeting: current status and uses. Int J Mol Sci. 2016;17 (9):1440. doi:10.3390/ijms17091440

19. Benvegnú DM, Barcelos RCS, Boufleur N, et al. Haloperidol-loaded polysorbate-coated polymeric nanocapsules decrease its adverse motor side effects and oxidative stress markers in rats. Neurochem Int. 2012;61(5):623-631. doi:10.1016/j.neuint.2012.06.015

20. Amani H, Kazerooni H, Hassanpoor H, Akbarzadeh A, PazokiToroudi H. Tailoring synthetic polymeric biomaterials towards nerve tissue engineering: a review. Artif Cells Nanomed Biotechnol. 2019;47(1):3524-3539. doi:10.1080/21691401.2019.1639723

21. Hirsjärvi S, Dufort S, Bastiat G, et al. Surface modification of lipid nanocapsules with polysaccharides: from physicochemical characteristics to in vivo aspects. Acta Biomater. 2013;9(5):6686-6693. doi:10.1016/j.actbio.2013.01.038

22. Vieira SM, Michels LR, Roversi K, et al. A surface modification of clozapine-loaded nanocapsules improves their efficacy: A study of formulation development and biological assessment. Colloid Surf B Biointerfaces. 2016;145:748-756. doi:10.1016/j.colsurfb.2016.05.065

23. Frank LA, Contri RV, Beck RCR, Pohlmann AR, Guterres SS Improving drug biological effects by encapsulation into polymeric nanocapsules. Wiley Interdiscip Rev Nanomed Nanobiotechnol. 2015;7(5):623-639. doi:10.1002/wnan.1334

24. Kaur IP, Bhandari R, Bhandari S, Kakkar V. Potential of solid lipid nanoparticles in brain targeting. $J$ Control Release. 2008;127 (2):97-109. doi:10.1016/j.jconrel.2007.12.018

25. Fessi H, Puisieux F, Devissaguet JP, Ammoury N, Benita S. Nanocapsule formation by interfacial polymer deposition following solvent displacement. Int J Pharm. 1989;55:R1-R4. doi:10.1016/ 0378-5173(89)90281-0

26. Michels L, Bajerski L, Maciel T, Colome L, Haas S. Quinine-loaded polymeric nanoparticles: validation of a simple HPLC-PDA method to determine drug entrapment and evaluation of its photostability. $J \mathrm{Appl}$ Pharm Sci. 2016;6(02):009-015. doi:10.7324/JAPS.2016.60202

27. Derendorf H, Garrett ER. Pharmako-Kinetik Einfuhrung in die Theorie Und Relevanz Fur Die Arzneimittel Therapie. Stuttgart: Deutscher Apotheker -Verlag; 1987.

28. Bayne K. Revised guide for the care and use of laboratory animals available. Am Physiol Soc. 1996;39(4):199.

29. Pedroni H. Desenvolvimento de modelo de malária experimental em ratos wistar e avaliação da influência da infecção no perfil farmacocinético e na distribuição tecidual da; 2005. Available from: http://www.lume.ufrgs.br/ handle/10183/6074. Accessed December 4, 2019.

30. Peters W. The chemotherapy of rodent malaria, XXII. The value of drug-resistant strains of P. berghei in screening for blood schizontocidal activity. Ann Trop Med Parasitol. 1975;69(2):155-171. doi:10.1080/00034983.1975.11686997

31. dos Santos Chaves P, Ourique AF, Frank LA, Pohlmann AR, Guterres SS, Beck RCR. Carvedilol-loaded nanocapsules: mucoadhesive properties and permeability across the sublingual mucosa. Eur J Pharm Biopharm. 2017;114:88-95. doi:10.1016/j.ejpb.2017.01.007

32. Frank LA, Sandri G, D'Autilia F, et al. Chitosan gel containing polymeric nanocapsules: a new formulation for vaginal drug delivery. Int J Nanomedicine. 2014;9(1):3151-3161. doi:10.2147/IJN.S62599

33. Beber TC, de Andrade DF, dos Santos Chaves P, Pohlmann AR, Guterres SS, Ruver Beck RC. Cationic polymeric nanocapsules as a strategy to target dexamethasone to viable epidermis: skin penetration and permeation studies. J Nanosci Nanotechnol. 2016;16 (2):1331-1338. doi:10.1166/jnn.2016.11670

34. De Sousa Lobato KB, Paese K, Forgearini JC, Guterres SS, Jablonski A, De Oliveira Rios A. Characterisation and stability evaluation of bixin nanocapsules. Food Chem. 2013;141(4):3906-3912. doi:10.1016/j.foodchem.2013.04.135
35. Venturini CG, Jäger E, Oliveira $\mathrm{CP}$, et al. Formulation of lipid core nanocapsules. Colloids Surf a Physicochem Eng Asp. 2011;375(1-3):200-208. doi:10.1016/j.colsurfa.2010.12.011

36. Pohlmann AR, Fonseca FN, Paese K, et al. Poly( $\varepsilon$-caprolactone) microcapsules and nanocapsules in drug delivery. Expert Opin Drug Deliv. 2013;10(5):623-638. doi:10.1517/17425247.2013.769956

37. Schaffazick SR, Guterres SS, De Lucca Freitas L, Pohlmann AR. Caracterização e estabilidade físico-química de sistemas poliméricos nanoparticulados para administração de fármacos. Quim Nova. 2003;26(5):726-737. doi:10.1590/S0100-40422003000500017

38. Schaffazick SR, Pohlmann AR, De Cordova CAS, Creczynski-Pasa TB, Guterres SS. Protective properties of melatonin-loaded nanoparticles against lipid peroxidation. Int $J$ Pharm. 2005;289(1-2):209-213. doi:10.1016/j.ijpharm.2004.11.003

39. dos Santos PP, Paese K, Guterres SS, et al. Development of lycopene-loaded lipid-core nanocapsules: physicochemical characterization and stability study. $J$ Nanoparticle Res. 2015;17(2). doi:10.1007/s11051-015-2917-5

40. Schaffazick SR, Pohlmann AR, Mezzaliraa G, Guterres SS. Development of nanocapsule suspensions and nanocapsule spray-dried powders containing melatonin. J Braz Chem Soc. 2006;17(3):562-569. doi:10.1007/ s13398-014-0173-7.2

41. Schuh RS, Bruxel F, Teixeira HF. Physicochemical properties of lecithin-based nanoemulsions obtained by spontaneous emulsification or high-pressure homogenization. Quim Nova. 2014;37(7):1193-1198. doi: $10.5935 / 0100-4042.20140186$

42. Hafner A, Lovrić J, Voinovich D, Filipović-Grčić J. Melatoninloaded lecithin/chitosan nanoparticles: physicochemical characterisation and permeability through Caco-2 cell monolayers. Int J Pharm. 2009;381(2):205-213. doi:10.1016/j.ijpharm.2009.07.001

43. Washington $\mathrm{C}$. The stability of intravenous fat emulsions in total parenteral nutrition mixtures. Int $J$ Pharm. 1990;66(1-3):1-21. doi:10.1016/0378-5173(90)90379-I

44. Paese K, Jäger A, Poletto FS, et al. Semisolid formulation containing a nanoencapsulated sunscreen: effectiveness, in vitro photostability and immune response. J Biomed Nanotechnol. 2009;5(3):240-246. doi:10.1166/jbn.2009.1028

45. Weber J, Funk NL, Motta MH, et al. Association of borage oil and betamethasone dipropionate in lipid-core nanocapsules: characterization, photostability and in vitro irritation test. J Nanosci Nanotechnol. 2016;16(2):1354-1362. doi:10.1166/jnn.2016.11674

46. Jäger E, Venturini CG, Poletto FS, et al. Sustained release from lipid-core nanocapsules by varying the core viscosity and the particle surface area. J Biomed Nanotechnol. 2009;5(1):130-140. doi:10.1166/jbn.2009.1004

47. Sari TP, Mann B, Kumar R, et al. Preparation and characterization of nanoemulsion encapsulating curcumin. Food Hydrocoll. 2015;43:540-546. doi:10.1016/j.foodhyd.2014.07.011

48. Santos SS, Lorenzoni A, Pegoraro NS, et al. Formulation and in vitro evaluation of coconut oil-core cationic nanocapsules intended for vaginal delivery of clotrimazole. Colloid Surf B Biointerfaces. 2014;116:270-276. doi:10.1016/j.colsurfb.2014.01.011

49. Contri RV, Ribeiro KLF, Fiel LA, AR P, Guterres SS. Vegetable oils as core of cationic polymeric nanocapsules: influence on the physicochemical properties. J Exp Nanosci. 2012;8(May):1-12. doi:10.1080/ 17458080.2011.620019

50. Durán-Lobato M, Muñoz-Rubio I, Holgado MÁ, Álvarez-Fuentes J, Fernández-Arévalo M, Martín-Banderas L. Enhanced cellular uptake and biodistribution of a synthetic cannabinoid loaded in surface-modified poly(lactic-co-glycolic acid) nanoparticles. $J$ Biomed Nanotechnol. 2014;10(6):1068-1079. doi:10.1166/jbn.2014.1806

51. Fresta M, Cavallaro G, Giammona G, Wehrli E, Puglisi G. Preparation and characterization of polyethyl-2-cyanoacrylate nanocapsules containing antiepileptic drugs. Biomaterials. 1996;17 (8):751-758. doi:10.1016/0142-9612(96)81411-6 
52. Guterres SS, Alves MP, Pohlmann AR. Polymeric nanoparticles, nanospheres and nanocapsules, for cutaneous applications. Drug Target Insights. 2007;2(April):147-157. doi:10.1177/1177392807 00200002

53. Anton N, Benoit JP, Saulnier P. Design and production of nanoparticles formulated from nano-emulsion templates-A review. J Control Release. 2008;128(3):185-199. doi:10.1016/j.jconrel. 2008.02.007

54. Christensen KL, Christensen J, Frokjaer S, Langballe P, Hansen LL. Influence of temperature and storage time after light exposure on the quinine monohydrochloride chemical actinometric system. Eur J Pharm Sci. 2000;9(3):317-321. doi:10.1016/S0928-0987(99)00072-X

55. De Azevedo Filho CA, de Filgueiras Gomes D, de Mélo Guedes JP, Batista RMF, Santos BS. Considerations on the quinine actinometry calibration method used in photostability testing of pharmaceuticals. J Pharm Biomed Anal. 2011;54(4):886-888. doi:10.1016/j.jpba. 2010.11.012

56. des Rieux A, Fievez V, Garinot M, Schneider YJ, Préat V. Nanoparticles as potential oral delivery systems of proteins and vaccines: A mechanistic approach. J Control Release. 2006;116 (1):1-27. doi:10.1016/j.jconrel.2006.08.013

57. Torchilin VP. Multifunctional nanocarriers. Adv Drug Deliv Rev. 2012;64(SUPPL.):302-315. doi:10.1016/j.addr.2012.09.031

58. Savian AL, Rodrigues D, Weber J, et al. Dithranol-loaded lipid-core nanocapsules improve the photostability and reduce the in vitro irritation potential of this drug. Mater Sci Eng C. 2015;46:69-76. doi:10.1016/j.msec.2014.10.011

59. Gehrcke M, Giuliani LM, Ferreira LM, et al. Enhanced photostability, radical scavenging and antitumor activity of indole-3-carbinolloaded rose hip oil nanocapsules. Mater Sci Eng C. 2016:6-13. doi:10.1016/j.msec.2016.12.006.

60. Pegoraro NS, Barbieri AV, Camponogara C, et al. Nanoencapsulation of coenzyme Q10 and vitamin E acetate protects against UVB radiation-induced skin injury in mice. Colloid Surf B Biointerfaces. 2017;150:32-40. doi:10.1016/j.colsurfb.2016.11.013

61. Quinteros DA, Ferreira LM, Schaffazick SR, Palma SD, Allemandi DA, Cruz L. Novel polymeric nanoparticles intended for ophthalmic administration of acetazolamide. J Pharm Sci. 2016;105 (10):3183-3190. doi:10.1016/j.xphs.2016.06.023
62. Gomes AP, Vitorino RR, Costa ADP, EG M, Oliveira MGDA, Siqueira-Batista R. Malária grave por Plasmodium falciparum. Rev Bras Ter Intensiva. 2011;23(3):358-369. doi:10.1590/S0103-507X2 011000300015

63. Chambers E, Mitragotri S. Prolonged circulation of large polymeric nanoparticles by non-covalent adsorption on erythrocytes. J Control Release. 2004;100(1):111-119. doi:10.1016/j.jconrel.2004.08.005

64. Paolino D, Cosco D, Moretti S, Puxeddu E. Gemcitabine-loaded biocompatible nanocapsules for the effective treatment of human cancer. Nanomedicine. 2012;8(2):193-201. doi:10.2217/nnm.12.101

65. Villa $\mathrm{CH}$, Anselmo AC, Mitragotri S, Muzykantov V. Red blood cells: supercarriers for drugs, biologicals, and nanoparticles and inspiration for advanced delivery systems. Adv Drug Deliv Rev. 2016. doi:10.1016/j.addr.2016.02.007

66. Amani H, Arzaghi H, Bayandori M, et al. Controlling cell behavior through the design of biomaterial surfaces: a focus on surface modification techniques. Adv Mater Interfaces. 2019;1900572:1-30. doi:10.1002/admi.201900572

67. Newton PN, Ward S, Angus BJ, et al. Early treatment failure in severe malaria resulting from abnormally low plasma quinine concentrations. Trans R Soc Trop Med Hyg. 2006;100(2):184-186. doi:10.1016/j.trstmh.2005.01.008

68. Chaves PDS, Frank LA, Frank AG, Pohlmann AR, Guterres SS, Beck RCR. Mucoadhesive properties of Eudragit ${ }^{\circledR} \mathrm{RS} 100$, Eudragit ${ }^{\circledR} \mathrm{S} 100$, and Poly( $\varepsilon$-caprolactone) nanocapsules: influence of the vehicle and the mucosal surface. AAPS PharmSciTech. 2018;19 (4):1637-1646. doi:10.1208/s12249-018-0968-5

69. Hassan UA, Hussein MZ, Alitheen NB, Ariff SAY, Masarudin MJ. In vitro cellular localization and efficient accumulation of fluorescently tagged biomaterials from monodispersed chitosan nanoparticles for elucidation of controlled release pathways for drug delivery systems. Int J Nanomedicine. 2018;13:5075-5095. doi:10.2147/IJN.S164843

70. Frank LA, Chaves PS, D'Amore CM, et al. The use of chitosan as cationic coating or gel vehicle for polymeric nanocapsules: increasing penetration and adhesion of imiquimod in vaginal tissue. Eur J Pharm Biopharm. 2017;114:202-212. doi:10.1016/j.ejpb.2017. 01.021
International Journal of Nanomedicine

\section{Publish your work in this journal}

The International Journal of Nanomedicine is an international, peerreviewed journal focusing on the application of nanotechnology in diagnostics, therapeutics, and drug delivery systems throughout the biomedical field. This journal is indexed on PubMed Central, MedLine, CAS, SciSearch ${ }^{\mathbb{}}$, Current Contents ${ }^{\mathbb{R}} /$ Clinical Medicine,

\section{Dovepress}

Journal Citation Reports/Science Edition, EMBase, Scopus and the Elsevier Bibliographic databases. The manuscript management system is completely online and includes a very quick and fair peer-review system, which is all easy to use. Visit http://www.dovepress.com/ testimonials.php to read real quotes from published authors. 